\title{
An integrated approach to determine left atrial volume, mass and function in hypertrophic cardiomyopathy by two- dimensional echocardiography
}

\author{
Ashraf M. Anwar • Osama I. I. Soliman · Attila Nemes • \\ Marcel L. Geleijnse $\cdot$ Folkert J. ten Cate
}

Received: 5 February 2007 / Accepted: 23 March 2007 / Published online: 31 May 2007

(C) Springer Science+Business Media B.V. 2007

\begin{abstract}
Methods The study included 25 hypertrophic cardiomyopathy (HCM) patients (15 non-obstructive and 10 obstructive) and 25 controls for assessment of left atrial (LA) volume, mass and function by twodimensional echocardiography. Measurement included mean LA diameter (LAD), LA mass $=\{($ mean LAD + anterior LA wall + posterior LA wall $)^{3}-$ mean $\left.\mathrm{LAD}^{3}\right\} \times 0.8+0.6$, LA volume $=$ [(8/3 $\pi \mathrm{L} \cdot \mathrm{A} 1 \cdot \mathrm{A} 2)$, where $\mathrm{L}$ is LA length, A1 and $\mathrm{A} 2$ are LA area in 4-chambers and 2-chambers, respectively] including maximum $\left(V_{\max }\right)$, minimum $\left(V_{\text {min }}\right)$, and pre-atrial contraction $\left(V_{\text {pre-A }}\right)$, total atrial stroke volume (TA-SV), TA emptying fraction (TAEF), active atrial SV (AA-SV), AA-EF, passive atrial SV (PA-SV), PA-EF, atrial expansion index (AEI), and LA kinetic energy $(\mathrm{LA}-\mathrm{KE})=1 / 2 \times \mathrm{AA}-$ $\mathrm{SV} \times P \times \mathrm{V}^{2}$.
\end{abstract}

A. M. Anwar · O. I. I. Soliman - A. Nemes ·

M. L. Geleijnse · F. J. ten Cate $(\bowtie)$

Department of Cardiology, Thoraxcenter, Erasmus

Medical Center, Room Ba 304, Dr Molewaterplein 40,

3015 GD Rotterdam, The Netherlands

e-mail: f.j.tencate@erasmusc.nl

A. M. Anwar · O. I. I. Soliman

Department of Cardiology, Al-Hussein University

Hospital, Al-Azhar University, Cairo, Egypt

A. Nemes

Second Department of Medicine and Cardiology Center,

Szeged University, Szeged, Hungary
Results LAD, LA mass, $V_{\max }, V_{\min }$, and $V_{\text {pre-A }}$ were significantly higher in HCM than controls. TA-SV and TA-EF were comparable in both HCM subgroups and controls. AA-SV and LA-KE were significantly higher in both HCM subgroups than controls. LA-KE was significantly higher in obstructive HCM than non-obstructive $(P<0.001)$. PA-EF and AEI were significantly lower in obstructive HCM than controls $(P<0.05)$.

Conclusion HCM is associated with increased LA size and augmented LA pump function especially obstructive type. LA conduit and reservoir functions are impaired in obstructive HCM.

Keywords Left atrial function - Hypertrophic cardiomyopathy $\cdot$ Left atrial volume $\cdot$ Left atrial mass

\section{Introduction}

Hypertrophic cardiomyopathy (HCM) is a relatively common form of genetic heart disease affecting approximately 1 in 500 in the general population [1, 2]. The pathophysiologic appearance of HCM is complex and includes dynamic left ventricular outflow tract (LVOT) obstruction, mitral regurgitation, diastolic dysfunction, myocardial ischemia and cardiac arrhythmia [3]. Diastolic dysfunction is more common than systolic dysfunction in HCM due to marked left ventricular hypertrophy, interstitial fibrosis and myocardial ischemia. These factors contribute 
to elevated left atrial (LA) and pulmonary vascular pressures [4]. LA modulates left ventricular filling through three components, a phase of reservoir component or expansion during systole, a conduit phase during diastole and an active contractile component during late diastole [5]. The active LA contraction has an important role in patients with reduced left ventricular compliance as it is compensating the decreased early filling [6, 7]. In HCM, stiffness of LA increases and this affects its reservoir function and may in turn affects the cardiac output [8]. LA enlargement is a common findings in HCM and associated with increased morbidity and mortality $[9,10]$. The present study aimed to assess LA size, mass and function in HCM patients compared with normal subjects.

\section{Patients and methods}

A retrospective study included 25 patients $(80 \%$ males, mean age $38 \pm 15$ years) with an established diagnosis of HCM [11] and good two-dimensional echocardiography (2DE) image quality. According to the type of HCM, patients were classified into two groups the non-obstructive group included 15 patients with resting LVOT gradient $<30 \mathrm{~mm} \mathrm{Hg}$, and the obstructive group included 10 patients with resting LVOT gradient $\geq 30 \mathrm{~mm} \mathrm{Hg}$. A group of 25 normal age-matched adults (mean age $35 \pm 16$ years) served as control subjects. None of them had evidence of cardiovascular disease by clinical examination, resting ECG and echocardiographic examination.

2DE was undertaken for HCM patients and control subjects with lying in the left lateral decubitus using both apical and parasternal views. 2DE studies were performed using a $3.5 \mathrm{MHz}$ transducer and a commercially available ultrasound system (Philips Sonos 7500, Best, The Netherlands). The following measures were obtained.

\section{Left ventricular (LV) function}

LV fractional shortening and ejection fraction were selected as a marker for systolic function. LV enddiastolic (LV-EDD) and end-systolic (LV-ESD) dimensions were measured using $\mathrm{M}$-mode from parasternal long axis view and thus LV fractional shortening were calculated by the traditional formula: Fractional shortening $(\%)=[$ LV-EDD - LV-ESD $] /$ LV-EDD\%. LV end-diastolic (LV-EDV) and endsystolic (LV-ESV) volumes were measured by 2D biplane modified Simpson's method and then ejection fraction was calculated by the formula: Ejection fraction $=[L V-E D V-L V-E S V] / L V-E D V$. Transmitral E/A ratio was defined by pulsed wave Doppler and used as a marker of LV diastolic function.

\section{Mitral regurgitation}

Mitral regurgitation was defined by colour Doppler and graded according to the maximum regurgitant jet area as mild (jet area $<4 \mathrm{~cm}^{2}$ ), moderate (jet area 4 $8 \mathrm{~cm}^{2}$ ), and severe (jet area $>8 \mathrm{~cm}^{2}$ ) [12]

\section{LA diameter (LAD)}

Maximum LAD was measured at three planes: antero-posterior from parasternal long axis view, medial-lateral and superior-inferior from apical fourchamber view. Then mean LAD (mean LAD) was defined as the average of the three LAD (See Fig. 1)
Fig. 1 Measurement of maximum left atrial diameter (LAD) at three planes: (A) antero-posterior LAD from parasternal long axis view, (B) mediallateral LAD and (c) superior-inferior LAD from apical four-chamber view
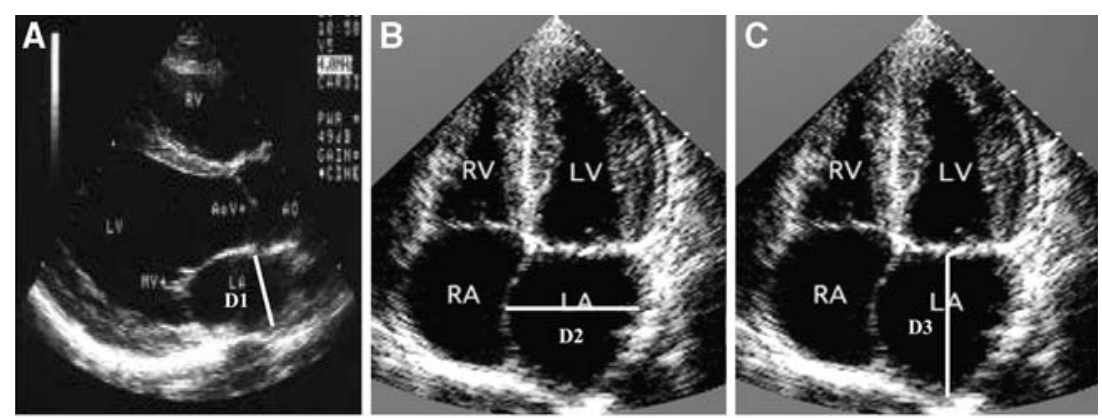

Mean $\mathrm{LAD}=(\mathrm{D} 1+\mathrm{D} 2+\mathrm{D} 3 \mid / 3$ 
LA mass

LA mass was calculated with the same formula applied for left ventricular mass [13] \{(mean LAD + anterior LA wall + posterior LA wall $)^{3}-$ mean $\left.\mathrm{LAD}^{3}\right\} \times 0.8+0.6$. Thickness of anterior and posterior LA walls was measured from parasternal long axis view. Zooming was used to discriminate between posterior LA wall and pericardium (See Fig. 2)

LA volume (LAV)

LAV was assessed according to the formula [6] 8/ $3 \pi \mathrm{L} \times \mathrm{A}_{1} \times \mathrm{A}_{2}$ where (L) is the LA longitudinal axis and $\left(A_{1}\right)$ is LA area at apical four-chamber and $\left(A_{2}\right)$ at apical two-chamber views. (L) was defined as the perpendicular line from mid point of the mitral valve plane to the tip of LA apex (See Fig. 3). LA area was obtained by manual tracing of LA endocardial border excluding LA appendage and the pulmonary veins when visualized. The superior border of atrial outline was a straight line connecting both sides of the leaflet base attachment points. LAV was calculated at three phases of ventricular cardiac cycle: maximum LAV $\left(V_{\max }\right)^{\text {at }}$ the end-systole just before mitral valve opening, minimum LAV $\left(V_{\min }\right)$ at end-diastole just before mitral valve closure, and LAV before atrial contraction $\left(V_{\text {Pre-A }}\right)$ : the last frame before mitral valve reopening. From the three $\mathrm{LAV}$, the following measurements were selected as indices of LA function and calculated according to previous studies [14, 15]:

(1) Total Atrial Stroke Volume (TA-SV) defined as $\left.V_{\max }-V_{\min }, 2\right)$ Total Atrial Emptying Fraction (TA-EF) defined as TA-SV/V $\mathrm{V}_{\max } \times 100 \%, 3$ ) Active Atrial Stroke Volume (AA-SV) defined as $V_{\text {Pre A }}-V_{\text {min }}$, 4) Active Atrial Emptying Fraction $(\mathrm{AA}-\mathrm{EF})$ defined as AA-SV $/ V_{\text {Pre A }} \times 100 \%, 5$ ) Atrial
Expansion Index (AEI) defined as TA-SV/ $\left.V_{\min } \times 100 \%, 6\right)$ Passive Atrial Stroke Volume (PA$\mathrm{SV})$ defined as $V_{\max }-V_{\text {Pre A }}$, and 7) Passive Atrial Emptying Fraction (PA-EF) defined as $\left(V_{\max }-V_{\text {Pre A }}\right) /$ $V_{\max } \times 100 \%$.

\section{LA kinetic energy (LA-KE)}

LA-KE [16] was calculated according to the formula $1 / 2 \times$ AA-SV $\times P \times \mathrm{V}^{2}$, where $P=1.06 \mathrm{~g} \mathrm{~cm}^{-3}$ (blood density), and (V) is the peak velocity of transmitral A wave was measured by pulsed wave Doppler.

To characterize the three phases of LA activity, PA-SV and PA-EF were defined as indices for LA conduit function, AA-SV, AA-EF, and LA-KE for LA pump function, and AEI for LA reservoir function.

\section{Statistical analysis}

All values were expressed as mean $\pm \mathrm{SD}$. Paired $t$-test was used for comparison between all HCM patients and controls. Independent sample $t$-test was used for comparison between both HCM subgroups and between each HCM subgroup and controls. The difference in the values between groups was considered significant if $P$ value $<0.05$. The statistical package used was SPSS version 12.1.

\section{Results}

Baseline criteria (See Table 1)

Both HCM patient group and controls were comparable with respect to age and sex distribution. All patients and controls were in sinus rhythm (mean heart rate $72 \pm 13$ beat per minute) and had normal LV
Fig. 2 M-mode obtained from parasternal long axis view (A). Zooming was used to measure anterior left atrial wall (B) and posterior left atrial
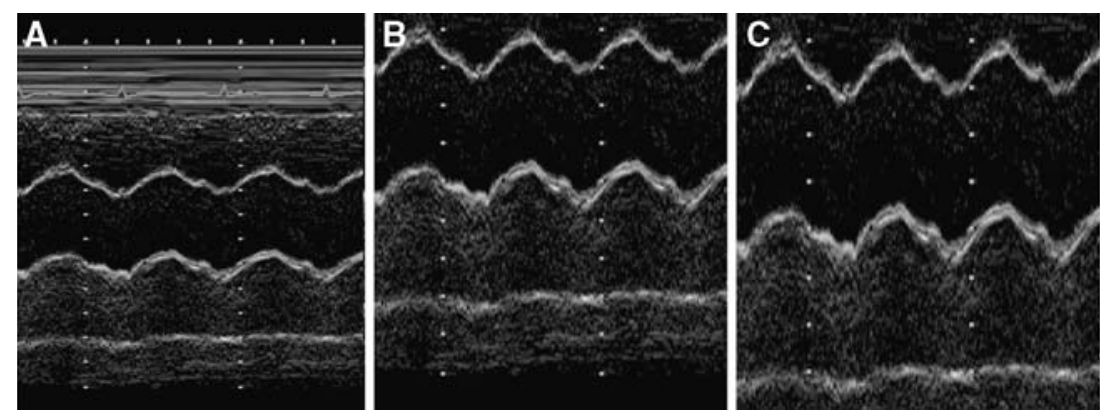
Fig. 3 Calculation of LAV using $2 \mathrm{DE}$ by manual tracing of LA endocardial border at apical four-chamber $\left(\mathrm{A}_{1}\right)$ and apical two chamber views $\left(\mathrm{A}_{2}\right), \mathrm{L}$ is the long axis, then apply the formula.: $8 / 3 \pi \mathrm{L} \times \mathrm{A}_{1} \times \mathrm{A}_{2}$

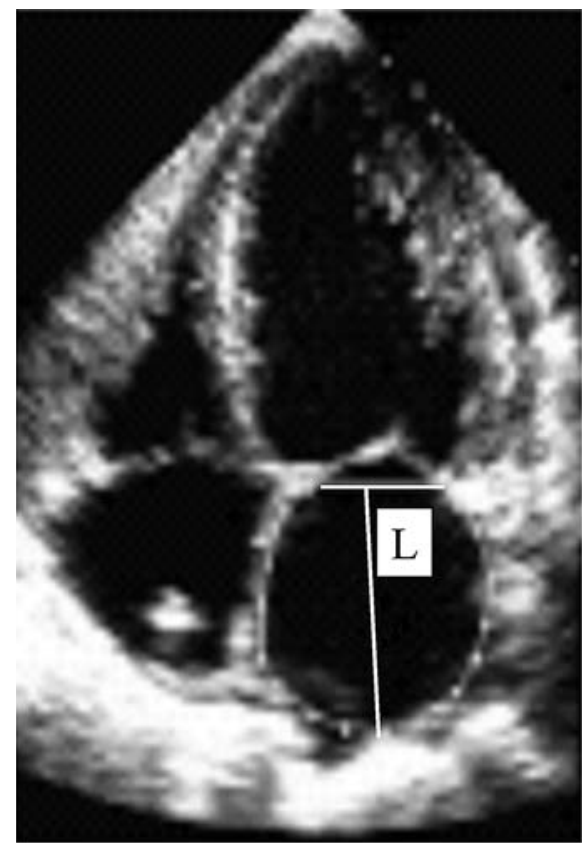

A4C

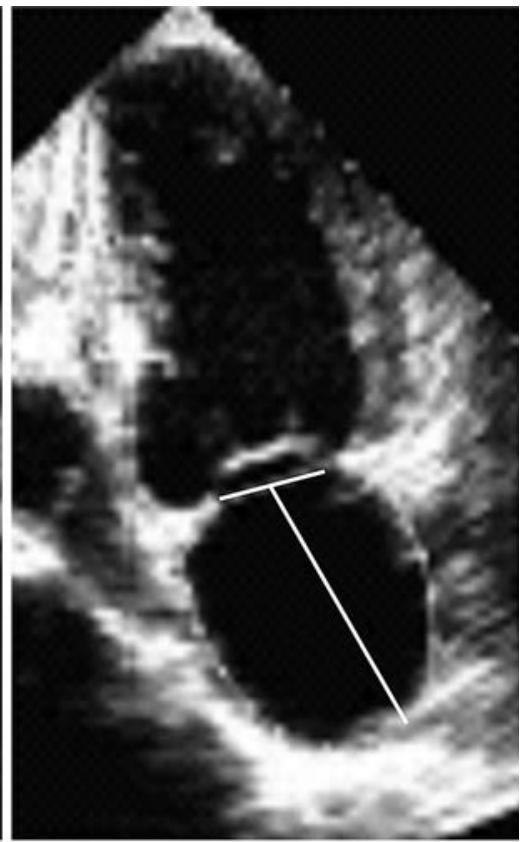

A2C systolic function. All HCM patients had type I diastolic dysfunction (increased A velocity, with an E/A ratio <1) [17]. Twenty patients $(80 \%)$ were under medications (10 patients under Verapamil, six under $\beta$-blockers, four under Amiodarone). LV-ESD and LV-ESV were significantly smaller in HCM patients than controls, while LV-EDD and LV-EDV showed no difference. LV-FS and LV-EF were significantly higher in HCM patients than controls $(P=0.001)$. HCM patients had a higher mean transmitral peak A velocity $(61.5 \pm 20.3$ vs. $39.7 \pm 9.9 \mathrm{~cm} / \mathrm{s}, P<0.01)$. The prevalence and severity of mitral regurgitation were significantly higher in HCM patients compared to controls as $80 \%$ of $\mathrm{HCM}$ patients had mitral regurgitation (60\% mild and $20 \%$ moderate to severe), while $20 \%$ of controls had mild mitral regurgitation $(P<0.0001)$. Both HCM patient subgroups (obstructive and non-obstructive) showed no significant differences in LV dimensions, volumes and function. Also, no significant difference in the prevalence and severity of mitral regurgitation was present.

\section{LA size and mass (Table 1)}

The maximum LAD at the three planes and the mean LAD were significantly larger in HCM patients than controls $(P<0.001)$. Thickness of anterior and posterior
LA walls showed no significant differences between HCM patients and controls. LA mass was significantly higher in HCM patients than controls $(89.8 \pm 37.2$ vs. $32.3 \pm 12.0 \mathrm{~g}, P<0.0001)$. No significant differences were found between HCM patient subgroups in the mean LAD, wall thickness and LA mass.

\section{LAV and total LA function (Table 2)}

LAV at the three phases of cardiac cycle $\left(V_{\max }, V_{\min }\right.$, and $\left.V_{\text {Pre-A }}\right)$ was significantly higher in both HCM patient subgroups than control group. TA-SV, TA-EF showed no significant differences between both HCM patient subgroups and control group. $V_{\max }$ was well correlated with the mean LAD $(r=0.89, P<0.0001)$.

\section{LA pump function}

AA-EF showed no significant differences between both HCM patient subgroups and control group, while AA-SV was significantly higher in both HCM patient subgroups than control group $(12.0 \pm 6.2 \mathrm{ml}$, $11.4 \pm 6.5 \mathrm{ml}$ vs. $7.3 \pm 4.0 \mathrm{ml}, P<0.001)$. No significant differences were found between $\mathrm{HCM}$ patient subgroups in AA-EF and AA-SV. LA-KE was significantly higher in $\mathrm{HCM}$ patients than controls $(24.3 \pm 18.9$ vs. $11.9 \pm 7.4$ kdynes $\mathrm{cm}, P=0.002)$. 
Table 1 Baseline clinical and echocardiographic data of HCM patients and controls

\begin{tabular}{|c|c|c|c|}
\hline & HCM patients $N=25$ & Normal control $n=25$ & $P$ value \\
\hline Age (yr) & $38 \pm 15$ & $35 \pm 15$ & \\
\hline Male gender $(\%)$ & $24(80 \%)$ & $18(60 \%)$ & \\
\hline Left ventricular FS (\%) & $38.4 \pm 9.6$ & $30.3 \pm 5.4$ & 0.03 \\
\hline Left ventricular EF (\%) & $71.1 \pm 17.7$ & $57.4 \pm 1.0$ & 0.001 \\
\hline Peak A velocity $(\mathrm{cm} / \mathrm{s})$ & $61.5 \pm 20.3$ & $39.7 \pm 9.9$ & 0.01 \\
\hline \multicolumn{4}{|l|}{ Mitral regurgitation } \\
\hline No & $5(20 \%)$ & $24(80 \%)$ & 0.0001 \\
\hline Mild & $15(60 \%)$ & $6(20 \%)$ & \\
\hline Moderate-severe & $5(20 \%)$ & $0(0 \%)$ & \\
\hline Antero-posterior LAD (mm) & $42.8 \pm 5.8$ & $34.1 \pm 4.2$ & 0.0001 \\
\hline Medial-lateral LAD (mm) & $45.6 \pm 9.9$ & $36.2 \pm 3.8$ & 0.001 \\
\hline Superior-inferior LAD (mm) & $60.8 \pm 9.0$ & $44.8 \pm 6.7$ & 0.0001 \\
\hline Mean LAD (mm) & $49.7 \pm 7.2$ & $38.4 \pm 4.0$ & 0.0001 \\
\hline Anterior left atrial wall (mm) & $3.6 \pm 1.0$ & $3.5 \pm 1.0$ & NS \\
\hline Posterior left atrial wall (mm) & $3.5 \pm 1.2$ & $3.1 \pm 1.1$ & NS \\
\hline Left atrial mass (g) & $89.8 \pm 37.2$ & $47.8 \pm 18.1$ & 0.0001 \\
\hline
\end{tabular}

Abbreviations: FS fractional shortening, EF ejection fraction, and LAD left atrial diameter

Table 2 Left atrial mass and function in non-obstructive HCM and obstructive HCM patients

\begin{tabular}{|c|c|c|c|c|c|}
\hline & Normal control $n=25$ & Non-obstructive $\operatorname{HCM} n=15$ & Obstructive HCM $n=10$ & $P$ value & \\
\hline & & & & $*$ & $* *$ \\
\hline Mean LAD (mm) & $38.4 \pm 4.0$ & $49.6 \pm 7.6$ & $49.9 \pm 7.0$ & 0.0001 & 0.0001 \\
\hline LA mass $(\mathrm{g})$ & $47.8 \pm 18.1$ & $86.8 \pm 41.1$ & $93.9 \pm 32.5$ & 0.002 & 0.001 \\
\hline $\mathrm{V} \max (\mathrm{ml})$ & $38.2 \pm 10.7$ & $64.7 \pm 26.7$ & $65.9 \pm 28.1$ & 0.002 & 0.009 \\
\hline $\mathrm{V} \min (\mathrm{ml})$ & $17.4 \pm 7.6$ & $32.7 \pm 22.1$ & $37.1 \pm 19.7$ & 0.02 & 0.008 \\
\hline V pre A $(\mathrm{ml})$ & $24.9 \pm 7.7$ & $44.7 \pm 24.7$ & $48.5 \pm 21.5$ & 0.008 & 0.005 \\
\hline TA-SV (ml) & $20.5 \pm 6.9$ & $32.0 \pm 8.9$ & $28.8 \pm 13.1$ & NS & NS \\
\hline TA-EF (\%) & $54.7 \pm 14.2$ & $53.6 \pm 13.8$ & $45.4 \pm 12.8$ & NS & NS \\
\hline AA-SV (ml) & $7.3 \pm 4.0$ & $12.0 \pm 6.2$ & $11.4 \pm 6.5$ & 0.001 & 0.001 \\
\hline AA-EF $(\%)$ & $31.4 \pm 17.8$ & $29.7 \pm 13.5$ & $25.4 \pm 12.8$ & NS & NS \\
\hline LA-KE (kdynes.cm) & $11.9 \pm 7.4$ & $18.3 \pm 12.5$ & $32.5 \pm 23.3^{\mathrm{a}}$ & 0.03 & 0.001 \\
\hline PA-SV (ml) & $13.4 \pm 5.7$ & $20.0 \pm 8.8$ & $17.5 \pm 9.8$ & 0.02 & NS \\
\hline PA-EF (\%) & $33.9 \pm 10.1$ & $34.0 \pm 14.8$ & $27.1 \pm 7.0$ & NS & 0.03 \\
\hline AEI $(\%)$ & $141.7 \pm 74.0$ & $134.8 \pm 74.4$ & $91.1 \pm 39.7$ & NS & 0.02 \\
\hline
\end{tabular}

Abbreviations: see text

* $P$ value between non-obstructive HCM patients and controls

** $P$ value between obstructive HCM patients and controls

${ }^{\text {a }} P$ value $<0.001$ between obstructive and non-obstructive HCM patients 
LA-KE was significantly higher in obstructive HCM patients than non-obstructive patients $(32.5 \pm 23.3 \mathrm{vs}$. $18.3 \pm 12.5$ kdynes $\mathrm{cm}, P<0.001)$.

\section{LA conduit function}

PA-SV was significantly increased in HCM patients than controls $(18.9 \pm 9.2$ vs. $13.4 \pm 5.7 \mathrm{ml}, P=0.01)$. PA-SV was significantly higher in non-obstructive HCM patients than controls $(20.0 \pm 8.8$ vs. $13.4 \pm 5.7 \mathrm{ml}, P=0.02$ ), while in obstructive $\mathrm{HCM}$ patients; it was comparable to controls $(17.5 \pm 9.8$ vs.13.4 $\pm 5.7 \mathrm{ml})$. PA-EF showed no significant difference between HCM patients and controls. PA-EF was significantly lower in obstructive HCM patients than controls $(27.1 \pm 7.0$ vs. $33.9 \pm 10.1, P=0.02)$, while in non-obstructive HCM patients; it was comparable to controls $(34.0 \pm 14.8$ vs. $33.9 \pm 10.1)$.

\section{LA reservoir function}

AEI showed no significant difference between HCM patients and controls. AEI was comparable in nonobstructive HCM patients and controls $(134.8 \pm 74.4 \%$ vs. $141.7 \pm 74.0 \%, \mathrm{P}=\mathrm{NS})$ but it was significantly lower in obstructive HCM patients than controls $(91.1 \pm 39.7 \%$ vs. $141.7 \pm 74.0 \%$, $P=0.02)$.

\section{Discussion}

In the present study, LA size was increased in HCM patients as assessed by LA dimension at three directions (antero-posterior, medial-lateral and superior-inferior) and by LAV at three phases of cardiac cycle. Thus, LA mass was increased in HCM patients compared to normal subjects. According to FrankStarling mechanism, LA pump function in HCM was increased to help ventricular filling as shown by increased AA-SV and LA-KE. LA reservoir and conduit functions were decreased in obstructive HCM patients as shown by decreased AEI and PA-EF. The clinical importance of this study is the close relationship of LA dimension and function with the development of serious complications as atrial fibrillation, cerebral infarction, and progressive heart failure in HCM as shown in previous studies [1820] as well as adverse outcome after myectomy [21]
The previous studies describing LA changes in HCM identified increased LAV [22, 23]. LA responds to the increased LAV by linear increase of LAD as shown in the present study. The nonlinear correlation between the increased LAD and increased LAV in previous studies [24] may be due to unidimensional M-mode assessment of LA size while, in the present study, the LA size was relied on 2D multidimensional assessment and the mean LA dimension was comparable to previous studies [10, 25].

The increased left ventricular wall thickness and elevated filling pressure in HCM frequently lead to development of abnormal diastolic function. In response to this overload, LA contractility increases to maintain adequate left ventricular filling. In accordance with previous studies [26, 27], AA-SV and LA-KE was significantly increased in our HCM patients than controls. Other studies reported no increase in LA contractility [28, 29]. The discrepancy between studies describing LA contractility in HCM is due to difference in hemodynamic conditions, atrio-ventricular interaction and left ventricular systolic function.

In HCM patients, the rate of left ventricular relaxation deteriorates due to markedly thickened and non-compliant left ventricle, which led to deterioration of LA conduit function. This was expressed by reduction in PA-EF in our HCM patients compared to controls.

LA reservoir function is determined by LA relaxation and mitral annulus displacement during left ventricular contraction [30]. In accordance with previous studies [8], AEI was significantly reduced in obstructive HCM patients, which indicates impaired LA relaxation. AEI showed no difference between our non-obstructive HCM patients and controls indicating preserved LA reservoir function.

\section{Study limitation}

The study had some limitations. The sample size of HCM patients (25 patients) is small but due to low prevalence of HCM $(0.2 \%)$. The assessment of LA mass is a new idea not discussed before by any imaging modalities. Of course it needs validation by autopsy or magnetic resonance imaging but at least it can pave a way for thinking about in further studies either by the same or another formula. Assessment of 
diastolic dysfunction was relied on transmitral flow by pulsed wave Doppler and other parameters by tissue Doppler imaging were not available. There are no data about prognostic value of atrial remodelling as a predictor for development of atrial fibrillation because it need long time follow up for large sample of patients. However data from previous studies could be relied on $[18,19]$.

\section{Conclusion}

Hypertrophic cardiomyopathy is associated with dilated LA and increased LAV that reflects the severity of LA overload. Higher AA-SV and LA-KE in HCM patients especially obstructive type indicates augmented LA pump function to overcome the high left ventricular filling pressure caused by severe left ventricular hypertrophy. Lower PA-EF and AEI in obstructive HCM patients indicate impaired LA reservoir and conduit functions. These findings may have clinical implication for the follow up of HCM patients

\section{References}

1. Maron BJ, Gardin JM, Flack JM, Gidding SS, Kurosaki TT, Bild DE (1995) Prevalence of hypertrophic cardiomyopathy in a general population of young adults. Echocardiographic analysis of 4111 subjects in the CARDIA Study. Coronary Artery Risk Development in (Young) Adults. Circulation 92:785-789

2. Maron BJ, Gardin JM, Flack JM, Gidding SS, Bild DE (1996) HCM in the general population. Circulation 94:588-589

3. Spirito P, Seidman CE, McKenna WJ, Maron BJ (1997) The management of hypertrophic cardiomyopathy. N Engl J Med 336:775-785

4. Braunwald E, Seidman CE, Sigwart U (2002) Contemporary evaluation and management of hypertrophic cardiomyopathy. Circulation 106:1312-13126

5. Hoit BD, Shao Y, Gabel M, Walsh RA (1994) In vivo assessment of left atrial contractile performance in normal and pathological conditions using a time-varying elastance model. Circulation 89:1829-1838

6. Stefanadis C, Dernellis J, Toutouzas P (2001) A clinical appraisal of left atrial function. Eur Heart J 22:22-36

7. Kagawa K, Arakawa M, Miwa H, Noda T, Nishigaki K, Ito Y, Hirakawa S (1994) [Left atrial function during left ventricular diastole evaluated by left atrial angiography and left ventriculography]. J Cardiol 24:317-325

8. Sanada H, Shimizu M, Sugihara N, Shimizu K, Ino H, Takeda R (1993) Increased left atrial chamber stiffness in hypertrophic cardiomyopathy. Br Heart J 69:31-35
9. Olivotto I, Cecchi F, Casey SA, Dolara A, Traverse JH, Maron BJ (2001) Impact of atrial fibrillation on the clinical course of hypertrophic cardiomyopathy. Circulation 104:2517-2524

10. Yang H, Woo A, Monakier D, Jamorski M, Fedwick K, Wigle ED, Rakowski H (2005) Enlarged left atrial volume in hypertrophic cardiomyopathy: a marker for disease severity. J Am Soc Echocardiogr 18:1074-1082

11. Maron BJ, McKenna WJ, Danielson GK, Kappenberger LJ, Kuhn H, Seidman CE, Shah PM, Spencer WH III, Spirito P, Ten Cate FJ, Wigle ED, Vogel RA, Abrams J, Bates ER, Brodie BR, Danias PG, Gregoratos G, Hlatky MA, Hochman JS, Kaul S, Lichtenberg RC, Lindner JR, O'Rourke RA, Pohost GM, Schofield RS, Tracy CM, Winters WL Jr, Klein WW, Priori SG, Alonso-Garcia A, Blomström-Lundqvist C, De Backer G, Deckers J, Flather M, Hradec J, Oto A, Parkhomenko A, Silber S, Torbicki A (2003) American college of cardiology/european society of cardiology clinical expert consensus document on hypertrophic cardiomyopathy: a report of the american college of cardiology foundation task force on clinical expert consensus documents and the european society of cardiology committee for practice guidelines. Eur Heart $\mathbf{J}$ 24:1965-1991

12. Spain MG, Smith MD, Grayburn PA, Harlamert EA, DeMaria AN (1989) Quantitative assessment of mitral regurgitation by Doppler color flow imaging: angiographic and hemodynamic correlations. J Am Coll Cardiol 13:585590

13. Devereux RB, Alonso DR, Lutas EM, Gottlieb GJ, Campo E, Sachs I, Reichek N (1986) Echocardiographic assessment of left ventricular hypertrophy: comparison to necropsy findings. Am J Cardiol 57:450-458

14. Poutanen T, Jokinen E, Sairanen H, Tikanoja T (2003) Left atrial and left ventricular function in healthy children and young adults assessed by three dimensional echocardiography. Heart 89:544-549

15. Blondheim DS, Osipov A, Meisel SR, Frimerman A, Shochat M, Shotan A (2005) Relation of left atrial size to function as determined by transesophageal echocardiography. Am J Cardiol 96:457-463

16. Stefanadis C, Dernellis J, Lambrou S, Toutouzas P (1998) Left atrial energy in normal subjects, in patients with symptomatic mitral stenosis, and in patients with advanced heart failure. Am J Cardiol 82:1220-1223

17. Appleton CP, Jensen JL, Hatle LK, Oh JK (1997) Doppler evaluation of left and right ventricular diastolic function: a technical guide for obtaining optimal flow velocity recordings. J Am Soc Echocardiogr 10:271-292

18. Eriksson MJ, Sonnenberg B, Woo A, Rakowski P, Parker TG, Wigle ED, Rakowski H (2002) Long-term outcome in patients with apical hypertrophic cardiomyopathy. J Am Coll Cardiol 39:638-645

19. Maron BJ, Olivotto I, Bellone P, Conte MR, Cecchi F, Flygenring BP, Casey SA, Gohman TE, Bongioanni S, Spirito P (2002) Clinical profile of stroke in 900 patients with hypertrophic cardiomyopathy. J Am Coll Cardiol 39:301-307

20. Higashikawa M, Nakamura Y, Yoshida M, Kinoshita M (1997) Incidence of ischemic strokes in hypertrophic car- 
diomyopathy is markedly increased if complicated by atrial fibrillation. Jpn Circ J 61:673-681

21. Woo A, Williams WG, Choi R, Wigle ED, Rozenblyum E, Fedwick K, Siu S, Ralph-Edwards A, Rakowski H (2005) Clinical and echocardiographic determination of long-term survival after surgical myectomy in obstructive hypertrophic cardiomyopathy. Circulation 111:2033-2041

22. Losi MA, Betocchi S, Grimaldi M, Spampinato N, Chiariello M (1994) Heterogeneity of left ventricular filling dynamics in hypertrophic cardiomyopathy. Am J Cardiol 73:987-990

23. Matsuda M, Matsuda Y (1996) Mechanism of left atrial enlargement related to ventricular diastolic impairment in hypertension. Clin Cardiol 19:954-959

24. Tani T, Tanabe K, Ono M, Yamaguchi K, Okada M, Sumida T, Konda T, Fujii Y, Kawai J, Yagi T, Sato M, Ibuki M, Katayama M, Tamita K, Yamabe K, Yamamuro A, Nagai K, Shiratori K, Morioka S (2004) Left atrial volume and the risk of paroxysmal atrial fibrillation in patients with hypertrophic cardiomyopathy. J Am Soc Echocardiogr 17:644-648

25. Maron BJ, Casey SA, Hurrell DG, Aeppli DM (2003) Relation of left ventricular thickness to age and gender in hypertrophic cardiomyopathy. Am J Cardiol 91:1195-1198
26. Sanada H, Shimizu M, Kita Y, Sugihara N, Shimizu K, Murakami T, Takeda R, Mifune J (1992) [Left atrial booster pump function in patients with hypertrophic cardiomyopathy and essential hypertension: evaluations based on left atrial pressure-volume relationship]. J Cardiol 22:99-106

27. Takeuchi Y, Yokota Y, Yokoyama M (1994) Left atrial backward ejection in symptomatic hypertrophic cardiomyopathy-assessment by transthoracic and transesophageal Doppler echocardiography. Jpn Circ J 58:809-20

28. Jarvinen VM, Kupari MM, Poutanen VP, Hekali PE (1996) Right and left atrial phasic volumetric function in mildly symptomatic dilated and hypertrophic cardiomyopathy: cine MR imaging assessment. Radiology 198:487-495

29. Nakao T, Shimizu M, Sugihara N, Kita Y, Shimizu K, Takeda R (1993) Preload dependency of left atrial pump function in hypertrophic cardiomyopathy. Jpn Circ J 57:47-54

30. Barbier P, Solomon SB, Schiller NB, Glantz SA (1999) Left atrial relaxation and left ventricular systolic function determine left atrial reservoir function. Circulation 100:427-436 